\title{
Using Voice Boards: pedagogical design, technological implementation, evaluation and reflections
}

\author{
Elisabeth Yaneske* and Briony Oates \\ School of Computing, Teesside University, Middlesbrough, UK \\ (Received 25 January 2010; final version received 30 September 2010)
}

\begin{abstract}
We present a case study to evaluate the use of a Wimba Voice Board to support asynchronous audio discussion. We discuss the learning strategy and pedagogic rationale when a Voice Board was implemented within an MA module for language learners, enabling students to create learning objects and facilitating peer-to-peer learning. Previously students studying the module had communicated using text-based synchronous and asynchronous discussion only. A common criticism of text-based media is the lack of non-verbal communication. Audio communication is a richer medium where use of pitch, tone, emphasis and inflection can increase personalisation and prevent misinterpretation. Feedback from staff and students on the affordances and constraints of voice communication are presented. Evaluations show that while there were several issues with the usability of the Wimba Voice Board, both staff and students felt the use of voice communication in an online environment had many advantages, including increased personalisation, motivation, and the opportunity to practice speaking and listening skills. However, some students were inhibited by feelings of embarrassment. The case study provides an in-depth study of Voice Boards, which makes an important contribution to the learning technology literature.
\end{abstract}

Keywords: Voice Boards; asynchronous audio discussion; learning objects; peerto-peer learning

\section{Introduction}

A Voice Board (VB) is an asynchronous audio discussion forum. This paper discusses the use of the VB produced by Wimba, a company providing collaborative learning software for education. The Wimba VB allows users to record and post audio, audio and text, and text-only messages without requiring additional software or knowledge of complex audio editing tools.

So far there has been little research into the use of VBs in learning and teaching. This paper therefore discusses a case study involving the use of the Wimba VB within a module on 'Language Learning and Teaching with ICT' (information and communication technology) taught by E, one of the paper authors. The paper is a 'wisdom of practice' report based on a personal account of change (Weimer 2006). Many such accounts have been criticised for failing to reference the educational literature and build on previous knowledge (Weimer 2006, 62). Particular attention has therefore been paid to the pedagogical rationale and theoretical basis for the VB-supported

\footnotetext{
*Corresponding author. Email: e.yaneske@tees.ac.uk
} 
learning strategy. The aims of the paper are to illustrate how VBs can be used as part of a learning strategy, and to share lessons learned about their use, with particular reference to the Wimba VB technology, to enable a deeper understanding of VBs within the learning technology community.

We discuss previous research into audio and VBs in education, and the rationale for the case study. We then explain the educational context of the selected case and describe the case-study methodology and how the learning technology was used. Finally, we discuss the case-study results, evaluate the effectiveness of the learning strategy and learning technology, and review the lessons learned.

\section{Background and rationale}

Synchronous communication involves real-time communication and requires all participants to be online at the same time (Salmon 2004). Our study is concerned with 'asynchronous audio discussion', where comments are recorded that can be listened to, and responded to, later.

Audio has been used in education for many years via radio, audiocassettes and CDs. Recently the ability to record and share audio has become available using audio files streamed online. These files are often called podcasts and can be downloaded. Historically, permanent mediums such as audiocassettes and podcasts suffer from a lack of interactivity (Junor 1992). VBs provide a means of overcoming this by allowing learners to interact with each other through an asynchronous audio discussion. There is a growing body of literature on using podcasts for learning as discussed below, but far less on the use of VBs.

Educationalists have adopted two pedagogical models when incorporating podcasts into their courses: the information transmission model and the social constructivist model. The most commonly used is the information transmission model; for example, podcasts of recorded lectures, seminar discussions, step-by-step videos of problem solutions, examination preparation information, supplementary material and induction information. Surveys have found students positive about such podcasts (Maag 2006; Chan, Lee, and McLoughlin 2006; Evans 2008; Malan 2007; Tynan and Colbran 2006). Common themes in student perceptions of podcasts' advantages are as follows:

- Repetition. Students can listen to/watch a podcast many times (Belanger 2005; Edirisingha, Rizzi, and Nie 2007; Maag 2006; Tynan and Colbran 2006). This can also lead to them spending increased time on learning and promote use of other resources (Maag 2006).

- Revision. Podcasts can help assessment preparation (Aldrich, Bell, and Batzel 2006; Evans 2008; Tynan and Colbran 2006).

- Flexibility. Podcasts can potentially be accessed anytime, anywhere on a mobile device. It is considered socially acceptable to be listening to your MP3 (Clark and Walsh 2004). This could lead to informal learning where students feel that learning 'just happens' without the need for deep concentration (Edirisingha, Rizzi, and Nie 2007). However, this may be more the case for radio magazine podcasts, whose aim is to transmit general points and stimulate interest, than for complicated subject material (Lee and Chan 2007).

- Convenience. They can be listened to at a time convenient to the student and allow students to catch up on missed lectures (Aldrich, Bell, and Batzel 2006; Maag 2006). 
- Tailoring. Students can review material at their own pace and selectively replay sections (Aldrich, Bell, and Batzel 2006; Tynan and Colbran 2006).

- Extra explanation. Podcasts can offer clarification, facilitating enhanced understanding of important or difficult concepts (Aldrich, Bell, and Batzel 2006; Belanger 2005).

- Motivation. They can be motivational by adding variety (Edirisingha 2006; Schlosser and Burmeister 2006), although this may be ascribed to the novelty effect (Malan 2007).

However, as yet there is little empirical evidence that podcasts following the transmission model are an effective learning tool. Malan (2007) found that students who were positive about the provision of podcasts had not accessed any of the podcasts available. Podcasts of lectures and problem solutions on an engineering course were accessed more often by lower-achieving students than the high achievers, but analysis did not show a correlation between podcast access and improved grade (Berger 2007).

Benefits have been claimed for particular types of students; for example, distance students, where there is little or no face-to-face contact with tutors and between students. Lee and Chan (2007) successfully used podcasts to address the pre-class anxieties of distance learners. Hearing the tutor's voice can help students to develop positive social bonds with her, and audio cues such as intonation and emphasis can guide students on where to channel their studies (Lee and Chan 2007). Audio cues can also help prevent misinterpretation (Schlosser and Burmeister 2006), and regular podcasts can help distance students with time management and organisation, enabling them to become more autonomous (Edirisingha 2006).

Audio can benefit students needing to hear authentic sounds, such as language students (Edirisingha, Rizzi, and Nie 2007; Cho and Carey 2001). Podcasts have been used to support language learners develop listening strategies (O'Bryan and Hegelheimer 2007). Podcasts of lectures also allow international students who are not studying in their first language to replay the lecture and make notes at their own pace (Belanger 2005; Schlosser and Burmeister 2006; Shannon 2006). Podcasts can make learning more accessible to students with certain disabilities such as visual impairment or dyslexia.

Podcasts have also been used to scaffold learners, a common example being audio feedback. Kates (1998) found audio feedback had particular benefits for part-time students who often had full-time jobs. Similar to distance students, they felt audio was more personalised and helped them feel valued as an individual by the tutor, and the tutor's voice tone indicated her reactions to the assignment. McCormack and Taylor (2006) found podcasts reduced the time and resources required to provide audio feedback on design work. When student presentations are recorded as an enhanced podcast and made available to their peers, peer evaluation can take place (Edirisingha, Rizzi, and Nie 2007; Lee 2006).

There are a few reports in the literature of using audio within a social constructivist model. Many MP3 players can be used to record audio as well as play it, enabling students to collect interview data, field notes, group discussions, and self-recording of oral assignments (Belanger 2005). In one study, students recorded interview data using iPods, and then presented their data analysis to the class via a podcast (Martin 2005). Chan, Lee, and McLoughlin (2006) asked second-year Information Technology students to produce podcasts to help first-year students. Vallance and Shibata (2008) put students into groups and asked them to produce interactive 
podcasts where they interviewed each other on a language learning-related topic, then added images, links and quizzes to the podcasts. These podcasts were then made available to the rest of the students as a learning aid. These studies show that students producing podcasts for their peers can promote collaborative peer-to-peer learning and individual reflection and cognition, as well as develop transferable skills such as communication skills, teamwork and problem-solving. Middleton (2009) suggests that the use of audio in online environments that had been predominantly text-based made them a more 'human space' by increasing the feeling of social presence; lack of social presence and feelings of isolation have been found to be a barrier to online learning (Muilenburg and Berge 2005; Newberry 2001).

In contrast to podcasts, there is little published research on using VBs. The Japancasting project initiated by Steve McCarty (2006) involves uploading podcasts for studying Japanese or English to a blog, which could be seen as equivalent to a VB, but this project has the disadvantage of requiring the podcast to be created on the user's computer and then uploaded. McIntosh, Braul, and Chao (2003) and Cho and Carey (2001) found VBs to be effective in enhancing the speaking and listening skills of language students. Marriott and Hiscock (2002) introduced VBs to stimulate online asynchronous discussion, but found that students expressed a preference for textbased discussion. This study did not determine the reason for the preference, but the learners were studying in a face-to-face environment where there were other opportunities for aural discussion that distance students do not have. Advantages of using VBs suggested in the literature include the following (McIntosh, Braul, and Chao 2003; Marriott and Hiscock 2002; Cho and Carey 2001; Ross 2003):

- Easy-to-use interface.

- Easier and more natural way to communicate.

- A richer medium allowing emotions and non-verbal cues to be conveyed.

- Ability to practise speaking and listening skills.

Common disadvantages include:

- Embarrassing to let others hear your recorded voice.

- Technical difficulties.

Our case study aim was to develop a deeper understanding of VBs as a pedagogical tool.

\section{The case study}

The case involved the MA module 'Language Learning and Teaching with ICT' within a University Education Department. This module introduces learners to technologies that could be used to support language teaching and encourages them to think critically about the pedagogic benefit of the technologies in their teaching practice. Students on this module could therefore be expected to be interested in the use of VBs and willing to try them. E is a learning and teaching technologist, not a language teaching specialist, and she was invited to try out VBs within the pedagogic strategy for the module.

The module runs for 12 weeks and each week learners study a new unit. In one unit, 'Using Audio and Video Technologies for Language Learning', students learn 
principles for selecting or making podcasts, and design tasks around them to support language learning. VBs were introduced into the learning strategy for this unit. The module is also supported by FirstClass, a virtual learning environment where students communicate using email, text-based discussion forums, and synchronous text-based chat.

Our research questions were as follows:

- What benefits did the students perceive when using a Wimba VB?

- What difficulties did the students experience when using a Wimba VB?

- How can a Wimba VB be incorporated in a learning strategy?

\section{Research methodology}

Eleven students took the module; their identities have been kept anonymous. One of the authors was the initiator of the innovation and, as a participant observer, was able to provide ongoing reflection on its progress. The university ethical approval process was followed and informed consent was obtained from all participants. All 11 students gave their user evaluation of the VB via an online survey implemented using SurveyMonkey (SurveyMonkey.com 2008) - see Appendix 1 for the questions used. Five students also participated in semi-structured interviews. Student views were also obtained via the synchronous chat session that followed the VB activity (see above). This took the form of an online group interview where students reflected on their experiences of using the VB. E also kept a personal research log to record her observations and reflections as a practitioner-researcher in the case study (Oates 2006).

It must be noted that these students may not be typical of all student cohorts as they were language students and therefore accustomed to using audio as a learning tool. Also, as they were studying the 'Language Learning and Teaching with ICT' module, they were motivated to learn new ICT tools to help them teach language skills.

\section{The learner characteristics}

Students studying the module are generally comfortable with ICT. They are expected to have prior knowledge of podcasts, including the ability to download them. As postgraduates they are all adult learners, typically in their late twenties. The study took place in 2008; the cohort comprised both full-time and part-time students, with most also in part-time or full-time employment, usually in education. Some were studying onsite and some as distance learners who were geographically dispersed in the United Kingdom, Africa, China, Poland and Greece.

Typically, the students are time-poor and those studying at a distance are unlikely to meet their tutors or peers face-to-face. It was hoped that the facility for students to communicate aurally would help build social bonds and trust within the learning community, and that this would encourage discussion.

\section{Learning strategy incorporating $\mathrm{VBs}$}

During the 'Using Audio and Video Technologies for Language Learning' unit, students learn principles for selecting or making podcasts and designing tasks around them to support language learning. They then put theory into practice by 


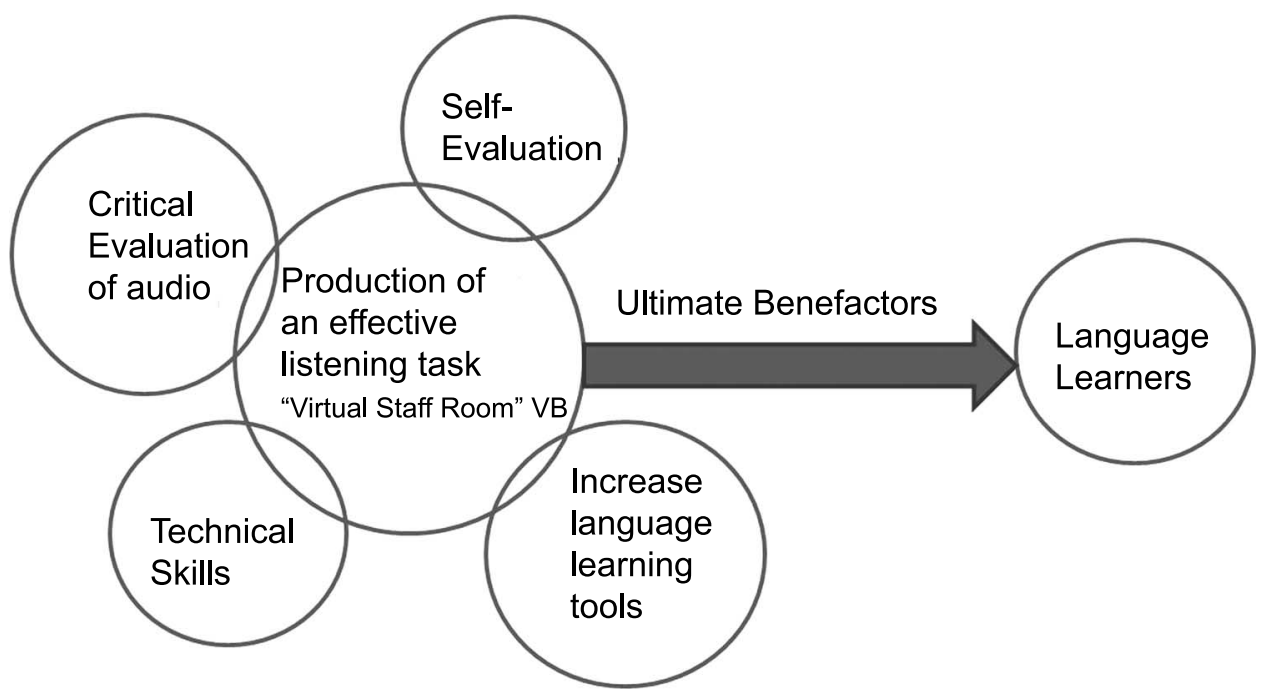

Figure 1. Development of the pedagogical toolkit.

creating a listening task to teach language points of their choice, by either using an existing podcast or creating their own, and designing a set of activities around it (Figure 1).

A VB was set up as a 'virtual staff room' to support the students. Students could use the VB to record a listening task (Figure 2), or they could upload a podcast they had created or obtained elsewhere (Figure 3).

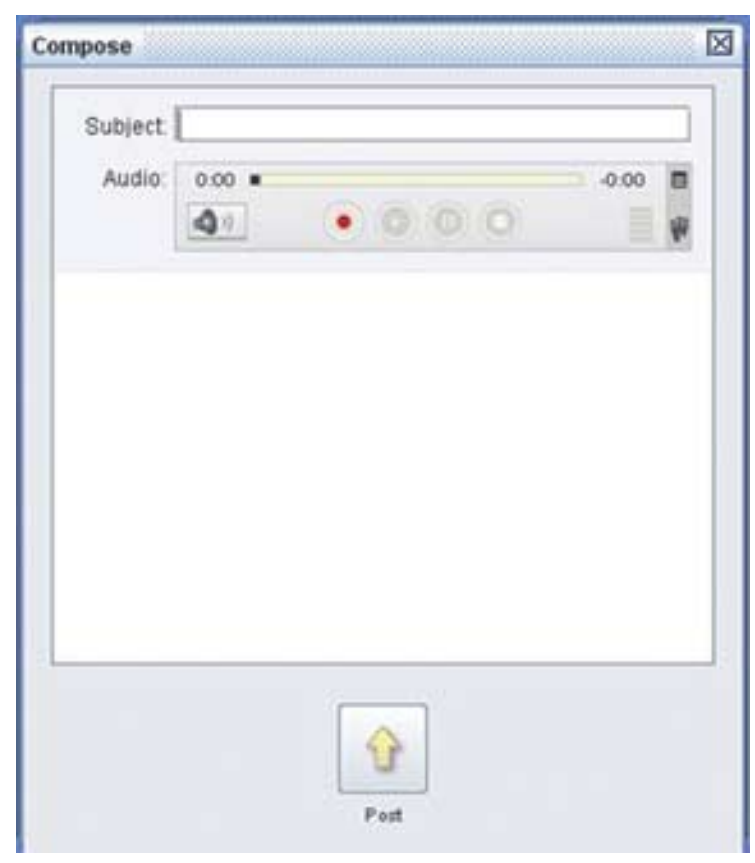

Figure 2. VB new message screen. 


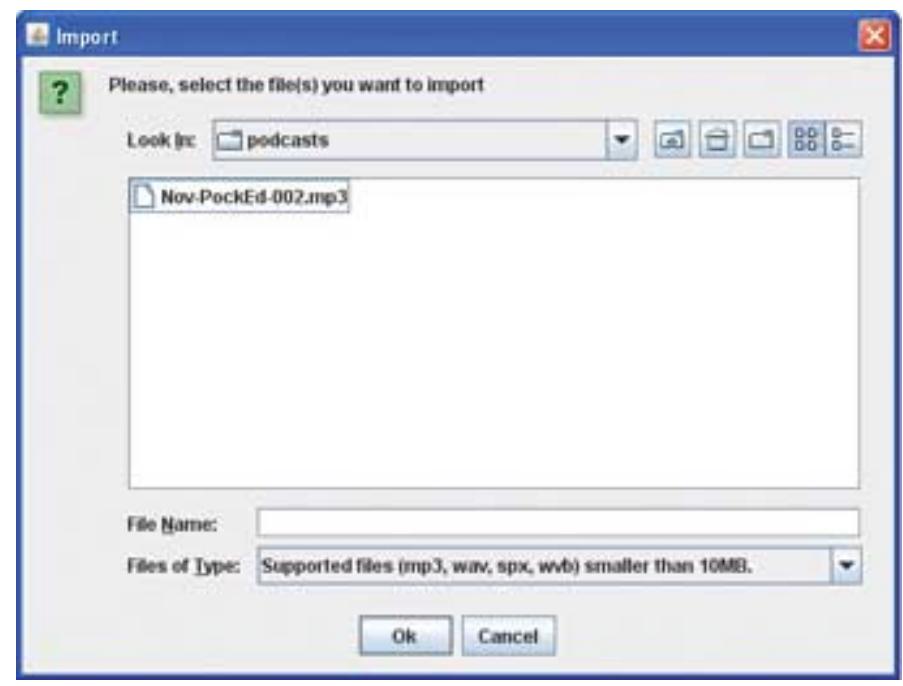

Figure 3. VB file upload screen.

Students had to upload their listening tasks to the virtual staffroom VB, so that they were all in one place to be shared with their peers and tutor (Figure 4). The VB was used by their tutor (E) to give formative feedback. Students were given three days to use the VB to supply feedback on at least two of their peers' work. As the task required students to evaluate the listening tasks of other students in their own time, a synchronous audio tool would not have been appropriate. The following questions were supplied for them to reflect on when reviewing their peers' work:

- Which materials would be most successful at promoting language learning?

- Why?

- What are the advantages and disadvantages of using a Wimba VB as a virtual staffroom (generally and in your own context)?

After the students had had time to reflect, they participated in a synchronous textbased group discussion to explore the questions in more detail and evaluate the VB from a user perspective. The VB was thus used to support the following learning outcomes:

- Develop an audio learning object based on synthesis and integration of appropriate sources and experience.

- Demonstrate technical competence in using the VB.

- Critically evaluate the VB.

\section{Pedagogic rationale}

This module was the students' first introduction to a VB so they required support to learn how to use the tool. The area of development where learners can only accomplish a task with assistance has been termed the 'zone of proximal development' by Vygotsky $(1978,86)$. Instructions were provided on how to access the VB. E also 


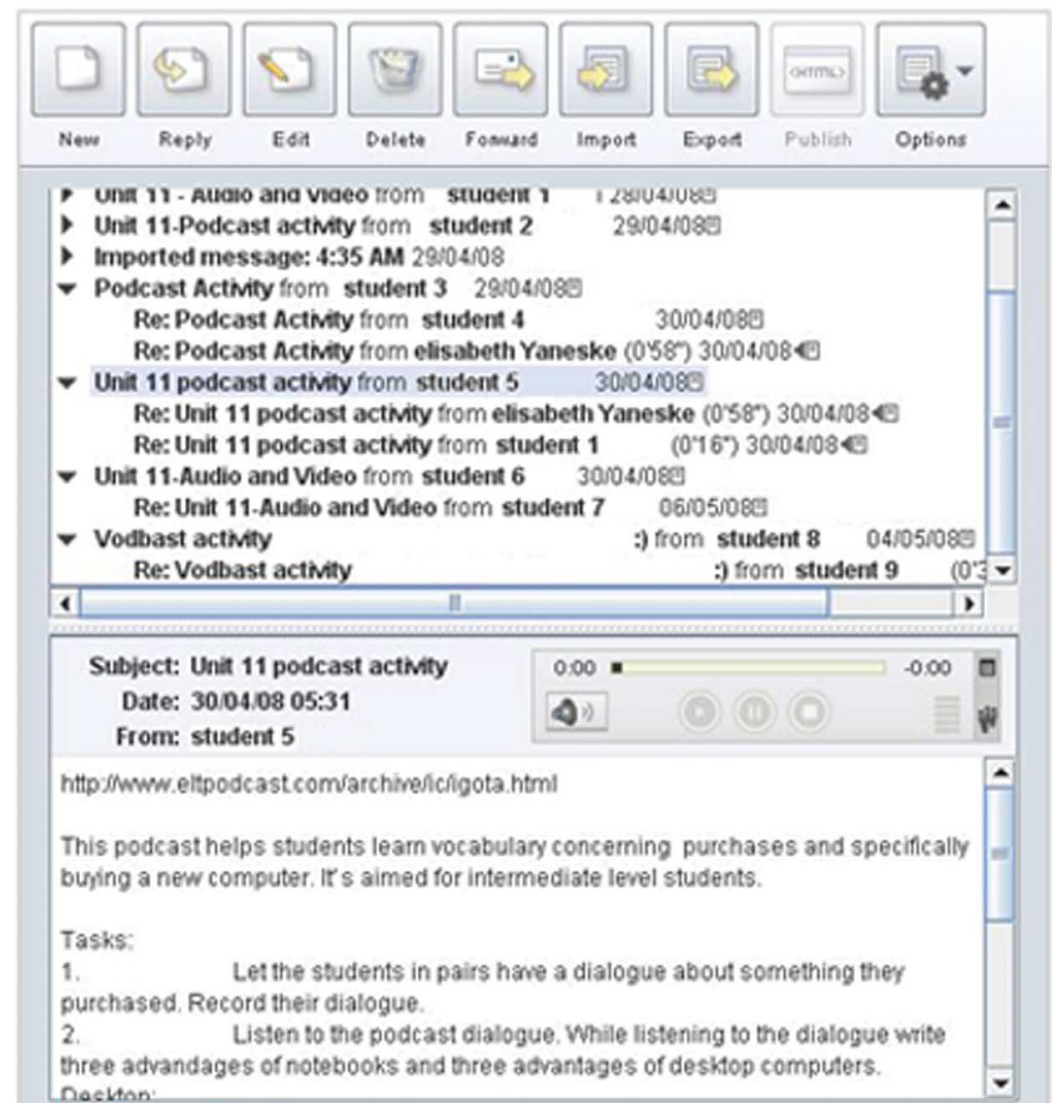

Figure 4. The virtual staffroom VB.

developed an optional Flash training application, which demonstrated visually how to use it. They were also given individual support as needed. Decreasing levels of support or 'scaffolding' (Wood, Bruner, and Ross 1976) were provided to students as they gained increasing VB competence.

The pedagaogical rationale was based on a social constructivist view of learning, which holds that individuals learn through experiences that cause them to question their existing beliefs, and through a process of internal reflection modify their beliefs and thus obtain new knowledge (Vygotsky 1978). E also believes that learning is inextricably linked with the social and cultural environment in which the experience takes place and that dialogue is an important part of this process (Laurillard 2002; Pask 1976; Salmon 2004; Garrison and Anderson 2003; Vygotsky 1978; Kolb 1984; Lave and Wenger 1991). She uses feedback to encourage tutor and peer dialogue around learning (Nicol and Macfarlane-Dick 2006), as well as peer dialogue. The aim of this dialogue is to create cognitive conflict that prompts reflection and leads to a transformation of knowledge. The task was designed to prompt dialogue around formative feedback from both tutors and peers. In effect, the students and the tutor scaffolded each other in learning about creating a listening task, using the VB. 


\section{Results and discussion}

This section discusses the students' and tutors' experiences and reflections on using the VB.

\section{What benefits did the students perceive when using a Wimba VB?}

The ability to post audio messages was identified as a positive feature of the VB in all three sets of evaluation results. Two strong themes emerged, the first of which was the 'human element' of hearing the voices of the tutor and peers. Students felt "hearing other people's voices helps to make a more personal connection to them". This suggests that audio communication did help to reduce feelings of isolation among students, confirming the increased social presence afforded by asynchronous audio reported by Middleton (2009) and Lee and Chan (2007). The second theme was the opportunity for students on this module to practise speaking, pronunciation and listening skills. One of the biggest perceived benefits for the students for whom English was a second language was the chance to hear native speakers and practise their own English skills. Where VBs have been used for language instruction, the ability to selfassess and improve one's own speaking and listening skills has been identified as a benefit for students (Cho and Carey 2001; McIntosh, Braul, and Chao 2003), but this was an unexpected benefit for this VB.

Also mentioned in both the questionnaire and the interviews was that students found it easier to identify their strengths and weaknesses in feedback delivered by audio. They felt audio gave an enhanced sense of meaning, emphasis, and emotion compared with text. These findings are similar to those found in previous studies of audio feedback (McCormack and Taylor 2006; Kates 1998). In interviews, students stated that audio was quick to record and provided 'immediate' interaction with other participants. Self-identified auditory learners found the audio feedback particularly motivating.

Other common positive features mentioned were the flexibility to post either text or audio messages, notification of new posts so that you did not have to keep logging in to check for them, and the ability to share audio files. Also, one student mentioned that while listening to the VB they were able to do other tasks concurrently. In the group interview, however, students mentioned that a down side of the notifications was feeling guilty that they did not have time to view all the messages. The group interviewees all agreed that the opportunity to learn about a new tool and consider how they could use it in future was a beneficial learning experience. Students' suggestions for using VBs to teach language learning included communicating with pen pals aurally, self-assessment and tutor assessment of speaking and listening, and a repository for student work.

\section{What difficulties did the students experience when using a Wimba VB?}

Frustrations with the Wimba VB interface were mentioned in all three sets of evaluation results. Two students reported difficulty in reading the text of a message, and four commented that the text size was small and hard to read. Students wanted a text area that could be resized and would support URLs, tables, pictures and different font sizes and colours. They would have liked the ability to archive, sort and search messages, and change the grouping of messages to suit their preference. Two students disliked the VB's lack of integration with FirstClass. Three disliked the VB's lack of support 
for attachments (other than audio), and that new messages were not flagged in any way. They wanted more advanced audio editing features and the ability to upload video.

Six students felt the asynchronous audio communication could inhibit discussion as it made "the rhythms of the conversation too slow". Four students mentioned a lack of confidence in posting audio because English was not their first language, and three because they felt self-conscious. The permanency of the audio was off-putting, lack of familiarity with asynchronous audio discussions caused embarrassment ("I don't like the sound of my own voice"). This embarrassment is a common feeling amongst students using VBs (McIntosh, Braul, and Chao 2003; Marriott and Hiscock 2002; Ross 2003). Three students expected that more people would use the audio facility, "if other people don't use the voice feature it demotivates you to use it". Four students would have preferred text feedback, and four students found audio feedback more difficult to analyse than text. This was exacerbated by poor sound quality. When they could not hear something properly or wanted to hear something again they had to replay the message repeatedly whereas text can be quickly skimmed. The lack of ability to skim audio quickly is a recognised disadvantage of VBs (Ross 2003).

Finally, a usability problem for students without administration rights to download software onto their computers was that Wimba VBs require the installation of Java Virtual Machine on the client computer. This meant those students using work computers or public computers such as a library computer had difficulty in arranging access to the VB.

\section{How can a Wimba VB be incorporated in a learning strategy?}

The adopted learning strategy was described above. Considering the original pedagogic objectives, listening tasks were created and uploaded, students received audio feedback from E, and students reflected on whether a VB could be useful in their own context. However, E was disappointed that there was not more discussion on the VB and that only two podcasts were uploaded to the board (the other nine students posted a URL to a podcast). Another time she would have a requirement that students upload a podcast or vodcast, to ensure that they learned that skill and that all the listening tasks would be collected in one place.

In her learning strategy E chose to provide feedback to students very quickly, to encourage discussion. On reflection, this may have inhibited discussion as it did not give the students a chance to reflect and comment amongst themselves before getting 'authoritative' feedback. In future, she would give the students an opportunity to comment first before adding her own thoughts. She would also ask students to indicate whether they would prefer to receive audio or text comments.

Eight students expressed the desire for synchronous voice communication for discussion as they felt that the non-immediate nature of asynchronous audio communication made debates more difficult. She would keep the possibility for asynchronous communication to let students and tutors post individualised comments and feedback, but would also introduce a synchronous audio session for a group discussion to reflect on the task.

She thought a further enhancement to the learning strategy would be an ice breaker activity, similar to that of McIntosh, Braul, and Chao (2003), to familiarise students with the technology and recording and listening to audio posts. This would allow students to overcome any technical barriers before using the VB and help alleviate the 
embarrassment of recording audio posts. It would also allow students to decide whether they had a preference for audio or text feedback so that they could request their preferred medium.

\section{Conclusion}

We have shown how VBs were incorporated into a learning strategy, with a detailed discussion of the underlying pedagogic rationale, and discussed the students' and tutor's evaluations of the Wimba VB. The students experienced both benefits and difficulties. E's perception was that the VB did increase the personalisation for students and the engagement of some students. It helped students practice their speaking, listening and pronunciation skills, and helped their interpretation of her feedback, but little discussion took place on the VB. E would use an audio discussion board again, but not the Wimba VB because of the usability problems experienced.

There is some potential bias in our account since one author, E, was the initiator of the change (introducing VBs) and so has a vested interest in its success. This potential bias is mitigated by including the students' evaluations as well as hers, and by having a second author, B, who was not involved in the module and who has challenged E's assertions and demanded the supporting evidence.

The findings reported are derived from just one case study: a single unit within one module with just 11 student participants. Generalisations from this single case study are therefore difficult. However, the technological difficulties reported here are likely to be experienced in other settings. The learning strategy incorporating VBs could readily be transferred to other settings where the tutor believes audio interaction could benefit student learning, such as cohorts that include visually impaired students or students wishing to practice their English speaking and hearing skills, and modules on counselling or conflict resolution where students' audio interaction skills need to be developed, yet they are separated by time or space.

We hope that other teachers and learning technologists will now have a deeper understanding of VBs and their use, and we look forward to further research examining how this technology can be used most effectively to enhance our students' learning.

\section{References}

Aldrich, D., B. Bell, and T. Batzel. 2006. Automated podcasting solution expands the boundaries of the classroom. In SIGUCCS '06: Proceedings of the 34th annual ACM SIGUCCS conference on User services, 1-4. New York: ACM Press.

Belanger, Y. 2005. Duke University iPod first year experience final evaluation report. http:// cit.duke.edu/pdf/reports/ipod_initiative_04_05.pdf (accessed November 19, 2007).

Berger, E. 2007. Podcasting in engineering education: A preliminary study of content, student attitudes, and impact. Innovate 4, no. 1. http://www.innovateonline.info/index.php?view $=$ article $\&$ id $=426 \mathrm{edn}$.

Chan, A., M.J.W. Lee, and C. McLoughlin. 2006. Everyone's learning with podcasting: A Charles Sturt University experience. In The 23rd annual conference of the Australasian Society for Computers in Learning in Tertiary Education, 111-20. Sydney: Sydney University Press.

Cho, S., and S. Carey. 2001. Increasing Korean oral fluency using an electronic bulletin board and Wimba based voiced chat. The Korean Language in America 6: 115-28.

Clark, D., and S. Walsh. 2004. iPod-learning. White paper. Brighton, UK: Epic Group.

Edirisingha, P. 2006. The 'double life' of an i-Pod: A case study of the educational potential of new technologies. Paper presented at the 12th International Conference on Technology 
Supported Learning \& Training, Online Education. https://ra.le.ac.uk/handle/2381/ 406? mode $=$ full\&submit_simple $=$ Show + full + item + record $($ accessed November 25, 2009).

Edirisingha, P., C. Rizzi, and M. Nie. 2007. Podcasting to provide teaching and learning support for an undergraduate module on English language and communication. Turkish Online Journal of Distance Education 8, no. 3: 87-107.

Evans, C. 2008. The effectiveness of m-learning in the form of podcast revision lectures in higher education. Computers \& Education 50, no. 2: 491-8.

Garrison, D., and T. Anderson. 2003. E-learning in the 21st century. London: Routledge Falmer.

Junor, L. 1992. Teaching by tape: Some benefits, problems, and solutions. Distance Education 13, no. 1: 93-107.

Kates, R. 1998. Tape recorders and the commuter student: Bypassing the red pen. Teaching English in the Two-Year College 25, no. 1: 21-4.

Kolb, D. 1984. Experiential learning: Experience as the source of learning and development. London: Prentice-Hall.

Laurillard, D. 2002. Rethinking university teaching: A framework for the effective use of educational technology. 2nd ed. London: RoutledgeFalmer.

Lave, J., and E. Wenger. 1991. Situated learning: Legitimate peripheral participation. Cambridge: Cambridge University Press.

Lee, M.J.W. 2006. Using blogs and podcasting to facilitate delivery and self/peer evaluation of oral presentation assessments. Learning Technology 8, no. 4: 28-30.

Lee, M.J.W., and A. Chan. 2007. Reducing the effects of isolation and promoting inclusivity for distance learners through podcasting. Turkish Online Journal of Distance Education 8, no. 1: 85-105.

Maag, M. 2006. iPod, uPod? An emerging mobile learning tool in nursing education and students' satisfaction. In The 23rd annual conference of the Australasian Society for Computers in Learning in Tertiary Education, 483-92. Sydney: Sydney University Press.

Malan, D.J. 2007. Podcasting computer science E-1. In SIGCSE '07: Proceedings of the 38th SIGCSE technical symposium on Computer science education, 389-93. New York: ACM Press.

Marriott, P., and J. Hiscock. 2002. Voice vs text-based discussion forums: An implementation of Wimba Voice Boards. In E-Learn conference, 640-6. Norfolk, VA: Association for the Advancement of Computing in Education (AACE).

Martin, C.E. 2005. Special education iPod project. http://hercules.gcsu.edu/ cmartin/ SpecialEd.htm (accessed November 5, 2010).

McCarty, S. 2005. Spoken Internet to go: Popularization through podcasting. JALT CALL 1, no. 2: 67-74.

McCormack, C., and M.J. Taylor. 2006. Electronic delivery of oral feedback on graphic design projects. In The 23rd annual conference of the Australasian Society for Computers in Learning in Tertiary Education, 525-8. Sydney: Sydney University Press.

McIntosh, S., B. Braul, and T. Chao. 2003. A case study in asynchronous voice conferencing for language instruction. Educational Media International 1469-5790 40, no. 1: 63-74.

Middleton, A. 2009. Beyond podcasting: Creative approaches to designing educational audio. ALT-J 17, no. 2: $143-55$.

Muilenberg, L., and Z. Berge. 2005. Student barriers to online learning: A factor analytic study. Distance Education 26, no. 1: 29-48.

Newberry, B. 2001. Raising student social presence in online classes. In Proceedings of WebNet 2001 World Conference on the WWW and the Internet, ed. W. Fowler and J. Hasebrook, 905-10. Orlando, FL: Association for the Advancement of Computing in Education (AACE).

Nicol, D.J., and D. Macfarlane-Dick. 2006. Formative assessment and self-regulated learning: A model and seven principles of good feedback practice. Studies in Higher Education 31, no. 2: 199-218.

Oates, B.J. 2006. Researching information systems and computing. London: Sage.

O'Bryan, A., and Hegelheimer, V. 2007. Integrating CALL into the classroom: The role of podcasting in an ESL listening strategies course. ReCALL 19, no. 2: 162-80.

Pask, G. 1976. Conversation theory: Applications in education and epistemology. Amsterdam: Elsevier. 
Ross, K.W. 2003. Asynchronous voice: A personal account. IEEE MultiMedia 10, no. 2: 70-4. Salmon, G. 2004. E-moderating: The key to teaching and learning online. 2nd ed. London: Routledge Falmer.

Schlosser, C.A., and M.L. Burmeister. 2006. Audio in online courses: Beyond podcasting. http://www.nova.edu/ burmeist/audio_online.html (accessed August 2, 2007).

Shannon, S.J. 2006. Why don't students attend lectures and what can be done about it through using iPod nanos? In The 23rd annual conference of the Australasian Society for Computers in Learning in Tertiary Education, 753-6. Sydney: Sydney University Press.

SurveyMonkey.com 2008. SurveyMonkey.com because knowledge is everything. http:// www.surveymonkey.com (accessed June 20, 2008).

Tynan, B., and S. Colbran. 2006. Podcasting, student learning and expectations. In The 23rd annual conference of the Australasian Society for Computers in Learning in Tertiary Education, 825-32. Sydney: Sydney University Press.

Vallance, M., and Shibata, Y. 2008. Effective implementation of interactive podcasting for the Web 2.0 generation. The JALT CALL Journal 4, no. 1: 60-74.

Vygotsky, L.S. 1978. Mind in society: The development of higher psychological processes. London: Harvard University Press.

Weimer, M. 2006. Enhancing scholarly work on teaching and learning: Professional literature that makes a difference. San Francisco, CA: Jossey-Bass.

Wood, D., J. Bruner, and G. Ross. 1976. The role of tutoring in problem solving. Journal of Child Psychology and Psychiatry 17: 89-100. 


\section{Appendix 1. Student 5979 Voice Board semi-structured interview schedule}
A. Have you read the interview consent form?
B. And are you happy to proceed?
C. Are you a distance student or an onsite student?
D. Are you studying part-time or full-time?

\section{Thinking about the Virtual Staff Room Voice Board...}

1. How did you expect the Virtual Staff Room Voice Board to be used?

2. What do you think of the Voice Boards as a collaborative tool?

3. In your experience, is this how the board was used in practice?

4. Do you think Voice Boards encourage discussion, or not?

\section{Thinking about the Voice Boards in general...}

5. Do you think there were any benefits to receiving audio feedback from the tutors and your peers or not?

6. What disadvantages, if any, are there to receiving audio feedback?

7. Did you listen to other participants' audio messages?

Yes/No

\section{If Yes}

How did you decide which messages to listen to?

Prompt: Was it a different selection process depending on the Voice Board?

Did you always listen to messages all the way through?

From your experience do you think there is an optimum length for an audio message?

If No

Why did you choose not to listen to other participants' audio messages?

8. Did you reply to other students' audio messages?

Yes/No

If Yes

How did you decide which messages to reply to?

If No

Why did you choose not to reply to other students' messages?

9. Would you say voice boards encourage discussion, or not?

10. Is there anything else that you'd like to share about your experiences of using the Voice Boards?

11. Was there anything about your experience of using the Voice Boards that you particularly liked, or not?

12. Was there anything about your experience of using the Voice Boards that you didn't like or found frustrating, or not?

13. What impact, if any, do you think that using Voice Boards for various activities on this module had on learning? 


\section{WIMBA Voice Board Project Survey}

This questionnaire is part of a research project being undertaken by Elisabeth Yaneske in partial requirement for her Doctorate of Education at the University of Leeds. The aim of this questionnaire is to research the student experience of using asynchronous audio discussion boards. The purpose of the research is to evaluate the asynchronous audio discussion boards rather than to evaluate the participants themselves. It is hoped that the results of this questionnaire will help to enhance the student learning experience.

By completing the questionnaire it will be understood that you have consented to participate in the project, and that you consent to the publication of the results of the project. Participation in this survey is voluntary and you are free to stop completing the questionnaire at any time without giving a reason. This is an anonymous questionnaire and the information that you give will be treated in the strictest confidence. It will not be possible to identify you individually in any reports published that arise from this research, however, you may be able to recognise your own words.

The data obtained will be stored electronically in a in a secure file in accordance with data protections laws and access will be restricted to the research team. The anonymous information that is collected may be shared with collaborators for research purposes. You have the right to withdraw your answers to the questionnaire at any time by contacting Elisabeth Yaneske at: e.yaneskegtees.ac.uk

Thank you very much for your help and feel free to contact me with any questions.

\section{WIMBA Voice Board Project Survey}

\section{What is your age?}
Under 25
$25-29$
$30-39$
40-49
50-59
60-69
$70+$

Please select your gender.
Male
Female

\section{WIMBA Voice Board Project Survey}

\section{Are you}

a distance student?

an onsite student?

What is your mode of study?
Full-time
Part-time

\section{What is your occupation?}

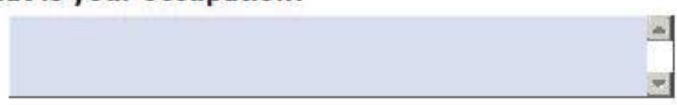


Is this module your first experience of using discussion forums (e.g. the 5979 Conference)?

Y Yes

No

WIMBA Voice Board Project Survey

In what other contexts have you used discussion forums?

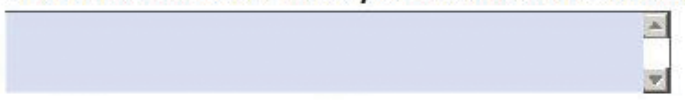

WIMBA Voice Board Project Survey

Did you have any problems accessing the Voice Boards?

C Yes

No

WIMBA Voice Board Project Survey

Please explain the problems you had trying to access the Voice Boards.

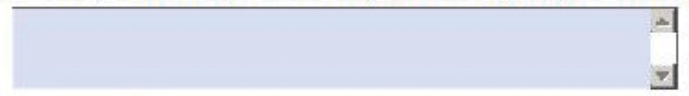

Were you able to access the Voice Boards?

$$
\begin{aligned}
& \text { Yes } \\
& \text { No }
\end{aligned}
$$

WIMBA Voice Board Project Survey 


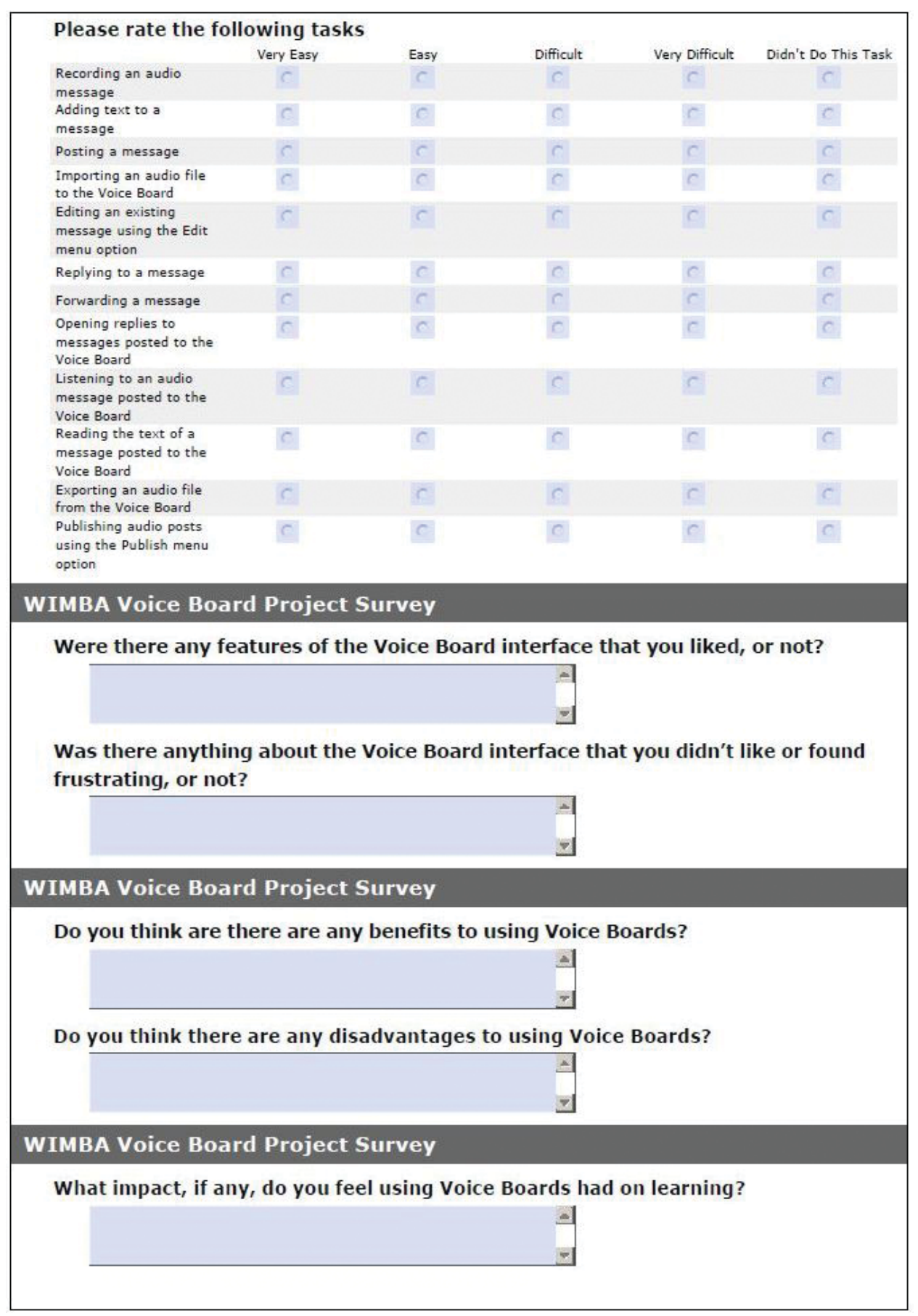


Did your experience of using the Voice Boards match your expectations? Please explain.

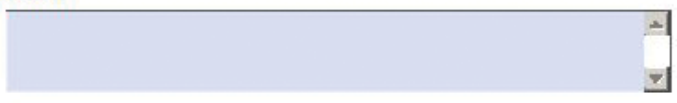

\section{WIMBA Voice Board Project Survey}

How, if at all, would you consider using Voice Boards in your own practice now or in the future?

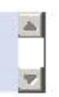

Do you have any recommendations for the use of Voice Boards in the future?

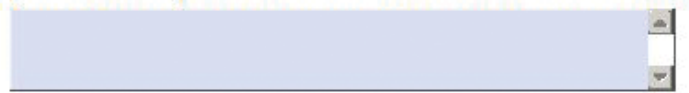

WIMBA Voice Board Project Survey

Would you be willing to take part in an interview? If yes, please enter your email address. 